EXEMPLARIa Classica

Journal of Classical Philology

20, 2016, pp. 163-186

ISSN 1699-3225

\title{
LAS METAMORFOSIS DE OVIDIO SEGÚN RAPHAEL REGIUS: ALGUNOS EJEMPLOS*
}

Rosa Ma Iglesias Montiel

Universidad de Murcia iglesias@um.es

Mª Consuelo Álvarez Morán

Universidad de Murcia

calvarez@um.es

\section{SUMMARY}

This paper analyses some passages from Raphael Regius' commentary on Ovid's Metamorphoses, in which the humanist provides suggestions and textual emendations. Many of his contributions have been accepted or discussed by the scholars all over the last centuries.

KEY WORDS

Ovid; Metamorphoses; Regius; Commentary.
RESUMEN

Este artículo examina algunos pasajes del comentario a las Metamorfosis ovidianas, en el que Rafael Regius aporta sugerencias e incluso enmiendas textuales, muchas de las cuales han sido aceptadas o discutidas por la crítica a lo largo de los últimos siglos.

Palabras Clave

Ovidio; Metamorfosis; Regius; Comentario.

Fecha de recepción: 9/05/2016

Fecha de aceptación y versión final: 14/07/2016

* Este trabajo se inserta en los Proyectos FFI2013-42671-P financiado dentro del Programa Estatal de Fomento de la Investigación Científica y Técnica de Excelencia, Subprograma de Generación del Conocimiento del MINECO, y 19246/PI/14 con cargo al Programa de Generación de Conocimiento Científico de Excelencia de la Fundación Séneca-Agencia de Ciencia y Tecnología. 
En las líneas que siguen intentaremos ofrecer algunas muestras de cómo el comentario a las Metamorfosis de Ovidio de Raphael Regius (en adelante $\mathrm{RR}$ ), con sus numerosas ediciones antes de que en 1543 Micyllus lo sometiera a revisión crítica y lo complementara, no solo era un intento de compilar las explicaciones destinadas a los escolares ${ }^{1}$, sino que aporta sugerencias e incluso enmiendas textuales, muchas de las cuales ha ido aceptando o discutiendo la crítica posterior a lo largo de los últimos siglos.

Numerosas fueron las ediciones y reediciones que se publicaron en Italia y en Francia a lo largo de los siglos XV y XVI. Para nuestro trabajo hemos seleccionado cinco a las que hemos dado unas siglas que nos permitirán citarlas con mayor comodidad; además, son de fácil consulta al haber sido digitalizadas.

Tres de ellas continúan la primera de Venecia de 1493 sin las novedades de la segunda edición de 1513 (base para la de Micyllus de 1543); todas ellas mantienen, por tanto, el texto de las Metamorfosis establecido por Bonus Accursius (edición de Milán de 1475), en la que incorpora sus propias emendationes a las editiones principes de 1471, la Bononiensis de F. Puteolanus y la princeps Romana de Ioh. Andreas de Buxis. ${ }^{2}$ En estas tres ediciones de Regio $^{3}$, el comentario va precedido, a imitación de aquellas en

${ }^{1}$ Un acercamiento lo hicimos en $\mathrm{M}^{\mathrm{a}} \mathrm{C}$. Álvarez, R. M. Iglesias, "El método de Raphael Regius, comentarista de Ovidio", en J. Costas Rodríguez, coord., Ad amicam amicissime

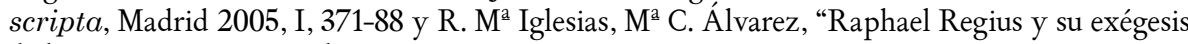
de las Metamorfosis ovidianas", RELat 6, 2007, 123-38.

${ }^{2}$ Para la enorme difusión que tuvieron las ediciones de las Metamorfosis y los comentarios (además del de RR) de que fueron acompañadas, cf. los dos artículos de G. Steiner, "SourceEditions of Ovid Metamorphoses (1471-1500)", TAPhA 82, 1951, 219-31 y "The Textual Tradition of the Ovidian Incunabula”, TAPhA 83, 1952, 312-8, así como F. Th. Coulson, "The Vulgate Commentary on Ovid's Metamorphoses". Mediaevalia 13, 1989, 29-61, y, más recientemente, K. L. McKinley, Reading the Ovidian Heroine. "Metamorphoses" Commentaries 1100-1618, Leiden 2001 (a RR le dedica las páginas 127-60).

${ }^{3}$ Las tres pueden ser consultadas en Internet, pues las de Venecia y de Lyon han sido divulgadas por Google y la de Parma (de la que haremos algunas observaciones más adelante), es de cómoda lectura en http://interclassica.um.es/biblioteca digital seneca/siglo xvi/metamorfosis. Ninguna de las consultadas tiene portada, pero podemos saber, o deducir, las fechas en que se publicaron: la de Venecia debe de ser una de las primeras reediciones, ya que no tiene ilustraciones y en la epístola final, dirigida a Paulo Cornelio, Patricio de Venecia, alude a las críticas que tuvo la primera de 1493 y a las correcciones que ha hecho in hac secunda editione; por otra parte, que la de Parma de 1505 lleve una epístola final inmediatamente después de esta de RR que reproduce, avala, junto con la falta de imágenes, la fecha temprana. La de Lyon, igualmente sin ilustraciones, indica con claridad: Lugduni impressum per Iacobum mallieti (sic). Die xxu februarii. Anno MCCCCLXXXXVII. En la de Parma, cuya epístola final de Peregrinus Solarus está dirigida al canónigo de Parma Pascasio Beliardo, además de la fecha, leemos el nombre de editor y grabador: Impressum Parmae Expensis et Labore Francisci Mazalis Calcographi diligentissimi, MDV Cal. Maii; a pesar de que su portada no aparece en el ejemplar de Murcia, la suponemos similar a la de la Biblioteca del Seminario de Santa Catalina de Mondoñedo (Lugo) reproducida en Biblioteca Digital Ovidiana. Ediciones Ilustradas de Ovidio (Siglos XV al XIX) en www.ovidiuspictus.net: Habebis candide lector P. Ovidii Nasonis Metamorphosin castigatissimam, cum Raphaelis Regii commentariis emendatissimis \& 
las que se basan, de un resumen de la Vida de Ovidio (de apenas un folio) y un índice de contenidos de cada libro (Index eorum quae quoque in libro metamorphoseos Ovidii continentur). Son cronológicamente las siguientes:

Ven1: una de las muchas re-ediciones de Venecia, sin ilustraciones y por lo general con los comentarios en columna paralela a los textos; carente de portada, sin duda fue publicada en fecha posterior a la que se lee escrita a mano en el ejemplar de la Universidad de Gante, ca. 1490. Sin numerar y con indicaciones en los márgenes de aquello que considera digno de ser resaltado (leyenda o comentario sobre lugares, etimología...)

Lug: publicada en Lyon en 1497, conservada en la Bibliothèque de la Ville de Lyon procedente del Convento de S. Ireneo; los índices remiten a las páginas en que se trata el contenido de cada episodio (una novedad con relación a las otras dos), lo que puede explicar que apenas haya indicaciones o llamadas en los márgenes; el texto está rodeado por el comentario. Sigue la edición de París de 1496, con la que se iniciaron las numerosas reimpresiones francesas ${ }^{4}$. Los folios $(r$ y $v)$ están numerados por el impresor.

Par: Uno de los ejemplares de la "edición de Parma de 1505", que alberga la Universidad de Murcia. Con el comentario en torno al texto. Muestra al inicio una Rosa de los Vientos así como ilustraciones tanto para el comienzo de cada libro como para determinados episodios, pues incorpora los grabados con los que el editor Giovanni Rosso da Vercelli (Iohannes Rubeus Vercellensis) ilustró la edición del Ovidio metamorphoseos vulgare de Venecia de 1497, traducción de Bonsignori, a la que se añaden en la Parmensis nuevas xilografías. Pese a que es sospechosa de ser un ejemplar de una "falsa edición", el texto es idéntico a la que presenta la genuina de Parma 1505.

capitulis figuratis decenter appositis, \& ab aliquo calchographi hactenus non impressis. Las tres ediciones tienen también en común presentar un índice de contenidos (Index eorum quae quoque in libro metamorphoseos Ovidii continentur), pero no el índice alfabético que elaboró Badius Ascensius y que sí aparece en las ediciones posteriores.

${ }^{4}$ Cf. A. Moss, Ovid in Renaissance France. A survey on the Latin editions of Ovid an commentaries printed in France before 1600, London 1982, 28-31.

${ }^{5}$ En el Coloquio Internacional Los clásicos Latinos en los orígenes de la imprenta:Textos, contextos y cultura impresa (ca. 1450-1540), celebrado en Madrid en noviembre de 2014, F. Díez Platas dedicó su intervención a la edición de Parma 1505, destacando la importancia del ejemplar que se conserva en Mondoñedo; recordó que el de Murcia pertenece a un grupo de aproximadamente veinte ejemplares que fueron modelo de las ediciones que se imprimieron en Lyon desde 1510, pese a ser, como afirmara J. Norton, Italian printers, 1501-1520, Cambridge 1958, 26, una "falsa edición" o "edición pirata" muy cercana a las que se publicaron en Venecia en los primeros años del s. XVI. Cf. de la misma Díez Platas, "Una presencia excepcional de Ovidio en Mondoñedo: la edición de Parma de 1505”, Estudios mindonienses: Anuario de estudios histórico-teológicos de la diócesis de Mondoñedo-Ferrol 28, 2012, 548-50. 
El grupo formado por las otras dos ediciones, ambas en la Bayerische Staatsbibliothek de Munich, contiene los añadidos hechos por RR en 1513, por lo que por una parte permiten deducir lo que el propio RR consideró que debía suprimirse de la primera edición y por otra comprobar la continua atención que prestaba a su Comentario:

Ven2: impresa en Venecia en $1521^{6}$; a los comentarios en torno al texto, a las ilustraciones y al índice de contenidos de cada libro (sin indicación de páginas), se añade un pormenorizado índice alfabético (vocum ac rerum index), sin duda continuando el que Badio Ascensio incorporó en 1501 (Quindecim Metamorphoseos libri diligentius recogniti, cum familiaribus commentariis et indice alphabetico ab Ascensio summa cura collecto) $)^{7}$, que remite a las páginas correspondientes.

Bas: edición de Basilea de 1543, en la que por primera vez aparecen las anotaciones de Micyllus ${ }^{8}$. Al índice alfabético, cuyo encabezado ya explicita el cuidado con que está elaborado y la facilidad que ofrece al lector para consultar lo que desee (Index rerum et vocabulorum, fabularum item et similium quae in hoc volumine habentur diligentissimus. a, priorem, $b$, posteriorem partem cuiusque columna denotante) le precede un listado no menos interesante: Autorum qui in hoc opere citantur, nomina. Están perfectamente delimitados los comentarios que pertenecen a Regius y las aclaraciones, matizaciones o discusiones que añadió Micyllus, quien, intentando "actualizar" la obra de Regius, gracias a su profundo conocimiento del griego, se vale de la segunda edición Aldina preparada por Andreas Naugerius en 1515 (publicada en febrero de 1516) y reeditada en 1533.

En la carta nuncupatoria a Francisco Gonzaga que precede a su exégesis, este gran conocedor del método de Quintiliano y de la Retórica en general

${ }^{6} \mathrm{Su}$ portada es muy similar a otras ediciones del mismo impresor (como la veneciana de 1509 que vemos en la Biblioteca Digital Ovidiana y que está en la biblioteca Pública de Tarragona); en ellas, tras el título propiamente dicho ( $P$. Ouidii Metamorphosis cum luculentissimis Raphaelis Regii enarrationibus, quibus cum alia quaedam ascripta sunt, quae in exemplaribus antea impressis non inueniuntur, tum eorum apologia quae fuerant a quibusdam repraehensa), aparece la información Impressum Venetiis per Georgium Rusconem de Mediolano, MDXXI.

${ }^{7}$ La edición fue impresa en Lyon, según leemos: Venundantur Lugduni ab Jacobo Huguetano ejusdem civitatis bibliopola et cive in vico Mercuriali, \&c. Y al final: Lugduni impressus per magistrum Nicolaum Wolf de Alemannia. Die XXIX. Novembr. Anno dni. M quingentessimo primo.

${ }^{8}$ Hay un ejemplar, también digitalizado, en Valencia. Su portada es explícita: P. Ovidii Nasonis Metamorphosews libri quindecim, cum commentariis Raphaelis Regii. Adiectis etiam Annotationibus IACOBI MICYLLI nunc primum in lucem editis, cum locupletissimo praeterea in haec omnia indice. Basileae per Ioan. Hervagium. Anno M.D.XLIII. 
que es RR, insiste en el rumbo nuevo que va a dar a sus comentarios, con un acercamiento más selectivo y basado en unos principios críticos estrictos, dando preeminencia al lenguaje poético, para así poner fin, dice, a la ignorancia de sus predecesores, a sus explicaciones pueriles de cuestiones triviales, a su manera de evadir las dificultades reales, y sobre todo a su descuido por los errores textuales, pues habían interpretado las corrupciones como si fueran el texto auténtico; ahora bien, eso no significa que él fuera un competente lector de las mejores lecturas pues para RR, como para la mayoría de sus contemporáneos, la corrección textual es una exhibición de erudición, no una colación científica de datos manuscritos ${ }^{9}$.

Cuando RR publicó sus Comentarios, ya habían visto la luz varias ediciones de la epopeya ovidiana, entre ellas la publicada en 1474 en Venecia por Johannes Bergomensis (Giovanni Planza o Perlanza de' Ruffinoni, 14431503), más conocido como Johannes Calphurnius Brixiensis ${ }^{10}$, el encarnizado enemigo de RR. Fruto de las continuas polémicas entre ellos, quizás iniciadas en Bérgamo, ciudad natal de ambos, fue que Planza consiguiera que en 1486 RR fuera apartado de las aulas de la Universidad de Padua (en la que desarrollaba su labor docente desde 1482), a la que sólo pudo volver después de la muerte de su oponente, pese a que hasta 1492, año en que se trasladó a Venecia, siguió viviendo en Padua y dando clases privadas ${ }^{11}$. Ese especial encono se trasluce en varios lugares de las anotaciones de RR, pues, si bien acepta algunas de las críticas y correcciones que sus lectores le han ido haciendo al leer su exégesis, se muestra, en cambio, particularmente despreciativo con "nonnulli" y totalmente combativo con las opiniones de Calfurnio, lo que se

${ }^{9}$ Las características de su obra y las intenciones de RR están muy bien resumidas por A. Moss tanto en lo concerniente a las ediciones francesas (Ovid in Renaissance France, 28-31) como en Latin Commentaries on Ovid from the Renaissance, Signal Mountain, Tennessee, 1998, 29-60.

${ }^{10}$ Para la edición de Calfurnius, cf. P. Pellegrini, "XEIP XEIPA NIחTEI. Per gli incunaboli di Giovanni Calfurnio, umanista editore”, Italia Medioevale e Umanistica 42, 2001, 186-90.

${ }^{11}$ Pueden verse los pormenores de su vida en diferentes repertorios y monografías, como: E. Hoefer, Nouvel biographie universelle depuis les temps les plus reculés jusqu'à nos jours, Paris 1852-1866, XLI, 839; Fr. A. Eckstein, Nomenclator Philologorum, Leipzig 1871; M. E. Cosenza, Biographical and Bibliographical Dictionary of the Italian Humanists and of the World of Classical Scholarship in Italy, 1300-1800, 5 vols. Boston 1962, IV, 3017-21; P. O. Kristeller, ed., Catalogus translationum et commentariorum: Medieval and Renaissance Latin Translations and Commentaries, Washington 1960-1984, III, 270 y IV, 338; P. G. Bietenholz, Th. B. Deutscher, eds., Contemporaries of Erasmus. A Biographical Register of the Renaissance and Reformation, Toronto-Buffalo-London, 3 vols, 1985-1987, III, 134; B. Guthmüller, Ovidio Metamorphoseos vulgare. Formen und Funktionen der volkssprachlichen Wiedergabe klassischer Dichtung in der italienischen Renaissance, Boppard am Rhein 1981, esp. 16, 187 y 236; Studien zur antiken Mythologie in der italienischen Renaissance, Weinheim 1986, 37-46; M. Winterbotom, "In praise of Raphael Regius”, en S. Döpp, ed., Antike Rhetorik und ihre Rezeption, Stuttgart 1999, 99-116; K. L. McKinley, Reading the Ovidian Heroine. 
comprueba ya desde las primeras líneas que escribe para explicar los cuatro versos $^{12}$ que constituyen el proemio de las Metamorfosis:

In nova fert animus mutatas dicere formas

Corpora: dii, coeptis (nam vos mutastis \& illas)

Aspirate meis primaque ab origine mundi

ad mea perpetuum deducite tempora carmen.

En efecto, después de dar una explicación, sin duda basada en Servio Aen. 1.8, sobre como suelen los épicos organizar sus poemas en tres partes (proponere, invocare, narrare), entiende que la propositio (v. 1) consiste en describir mutationes corporum in nouas figuras y que está expresada mediante una hipálage, y lo explica asi ${ }^{13}$ :

Mutatas formas: hoc est corpora in nouas formas figurasque mutata. Est enim hypallage poetis frequentissima. Nam corpora in nouas formas rectius mutari dicuntur quam contra. Eleganter autem operis inscriptionem expressit poeta. Nam metamorphosis transformatio ac formæ mutatio interpretatur.

Este razonamiento fue repetido o silenciado por los comentaristas posteriores, aunque ya desde mediados del s. XVI contó con opiniones en contra, como la de Ciofanus (Fallitur Regius, qui ait hoc dictum per Hypallagen ${ }^{14}$, que suele no tener buena opinión de RR, o la más ponderada de Gierig (Sed non opus est, ut ad hypallagen confugiamus $)^{15}$ y puede vislumbrarse también en la traducción que en 1964 hiciera Ruiz de Elvira para su edición española ("Es mi deseo exponer las transformaciones de los cuerpos en formas nuevas") ${ }^{16}$, pero fue, a lo que parece, muy criticada por Calfurnio, según se deduce del largo párrafo ${ }^{17}$ que añade a continuación $R R$, ensañándose

${ }^{12}$ Salvo indicación precisa, reproducimos con grafía actualizada los versos procedentes de la edición de Bonus Accursius que aparecen en las ediciones anteriores a 1543. Remitimos a las páginas citando las ediciones según las siglas que les hemos asignado; puesto que la ed. Ven 1 no está paginada por el impresor, la hemos numerado a imitación de las otras dos, es decir, iniciando tal numeración en la primera página del comentario propiamente dicho e indicando $r$ y $v$. Ocioso es indicar que estas primeras anotaciones pertenecen a la página $1 r$ de todas ellas.

${ }^{13}$ La puntuación refleja la edición que hemos llamado Ven1.

${ }^{14} \mathrm{La}$ primera edición de sus Observationes fue publicada en 1575 en Venecia. Nosotras hemos consultado la de Amberes: Herculis Ciofani Sulmonensis in P. Ovidii Nasonis Metamorphosin, ex xxIII antiquis libris Observationes. Quibus loci quamplurimi \& emendantur, \& aliorum quoque tum Graecorum, tum Latinorum poëtarum aut simili, aut etiam varia doctrina illustrantur, Antverpiae, ex officina Christophori Plantini, 1583.

${ }_{15}$ Th. E. Gierig, P. Ovidii Nasonis Metamorphoses ex recensione Burmanni, T. I, Lipsiae 1784.

${ }^{16}$ A. Ruiz de Elvira, P. Ovidio Nasón. Metamorfosis, vol. I, Barcelona 1964.

${ }_{17}$ Non ab re autem mihi uideor esse facturus. Si ineptis cuiusdam Ioannis Calphurnii 
con su adversario, al que tilda de arrogantissimus grammaticulorum ... insulsus e incluso nebulo. Le acusa de haber intentado destruir sus Comentarios desde el primer momento en que fueron publicados, de no querer admitir que el propio RR siempre estuvo dispuesto a aceptar críticas y enmendar lo que reconociera que estaba errado, de no aceptar, y ese es el mayor reproche del que se defiende $\mathrm{RR}$, que los poetas se sometan también a normas no dictadas por Cicerón y Quintiliano, ya que, lo que afirma Calfurnio que no está en ellos, puede ser utilizado por los dialectici; que Calfurnio no quiere entender, en suma, el objetivo que se propone RR al interpretar las obras de los poetas: que fueran imitados los oradores y no tan sólo los gramáticos, pues, si bien oratoria y gramática pueden coexistir, no debe ser ésta la que domina en un poema ni en el comentario que a se haga. Pero en este párrafo también se trasluce el deseo de menospreciar a su enemigo, pues, al aludir a su nombre latinizado: Insulsus igitur iste: qui se antea Calphurnium nunc Calpurnium uocare cœpit: cum a patre decepto ridicule scalfornia fuerit nuncupatus, estaba remitiéndose a las irónicas palabras que había escrito en 1490, en una disputatio con Calfurnio sobre unos pasajes de Plinio, Valerio Máximo y Cicerón; en ellas ${ }^{18}$ dice que creía que el nombre lo había creado $a$

grammaticulorum arrogantissimi cauillationibus nuper in has enarrationes meas sub nomine cuiusdam stolidi pædagogi editis obiter occurrere cœpero: idque breui: quo \& legentes dumtaxat admoneantur nos in apologia: \& recriminatione nostra quaecunque ab isto obiecta fuere: uana falsaque ostensuros: \& ad suspectam expositionem citius reuertamur. Insulsus igitur iste: qui.....: reprehendit: quod in prima harum commentationum editione: quam plerisque in locis corrumpendam sua malignitate curauit: ubi in secunda contra legitur: econuerso scriptum est: quod nusquam neque apud Ciceronem: neque apud Quintilianum inueniri ait: quamuis illo frequenter dialectici utantur. Atque hæc quidem prime cauillationis est summa. Perinde atque si nihil nisi quo Cicero Fabiusque ussi sunt: grammatice latineque dici possit. Aut quisque dialecticus Aristotelis sententia esse queat: nisi qui grammatice loquatur: aut ego in enarrandis poetarum operibus oratores et non grammaticos mihi proposuerim imitandos. Duae quidem hæ dictiones e atque conuerso: \& latine sunt: et nulla compositionis ratione copulari uetantur: cum econtrario etiam oratores nedum grammaticos poetarumque enarratores: qui in infimo: et quam uulgarissimo orationis genere uersantur passim usos esse uideamus. Quod si in meo de laudibus eloquentiæ panegyrico aliaue oratione isto locutione usus essem: merito fortasse reprehendi potuissem: quod uerba minus oratoria affectassem. In enarrationibus uero poetici operis hoc est in infimo genero orationis cum \& grammatice \& latine locutus sim: quam recte me nebulo iste reprehenderit doctorum sit iudicium: sed de istius ineptiis fœdissimisque erroribus reliqua in apologiam nostram differantur: ne sæpius cœptam expositionem interrumpere cogamur (Ven1, Lug y Par fol. $1 r$ ).

${ }_{18}$ Ego quidem cum primum te accepi spreto vero nomine Calphurnium malle nominari, putavi te aliquam paterni artificii rationem habuisse. Cum enim pater tuus et carbonariam fecerit et furnorum ferri fundendi calfaciendorum curam semper habuerit, credebam te ei, qui te genuit, aluit, educavit, ac ut bonis artibus instituereris nullis parcens impensis, suumque saepenumero vel necessariis defraudans genium, omni diligentia curavit, aliquid gratiae referre, memoriamque ipsius artificii ista nominis a calefaciundis furnis declinati arrogatione aeternitati comendare voluisse. Sed cum Calphurnium per ph. aspiratum, ut Graecum nomen scribendum asseras, video te ut in reliquis, sic in hoc quoque in patrem maxime impium semper fuisse. Is enim cum ardore tui videndi, quem senectuti baculum columenque sibi praeparatum esse 
calefaciundis furnis en homenaje a su padre, carbonero y siempre atento a que los hornos funcionaran adecuadamente, pero que en realidad se trataba de un sobrenombre que le diera su propio padre cuando fue a Bolonia buscando a su hijo, Zanino de nombre por entonces, y fue ignorado por éste, por lo que, al volver a su pueblo de Bérgamo respondió a una vecina que preguntaba por su hijo: Sed iam non Zaninus, sed Scalfornius nominatur, et quidem me bene scalforniavit, empleando un término no latino, scalforniare, que RR, para humillar más a su enemigo y demostrar la bajeza de sentimientos, "traduce" indicando que para los habitantes de Bérgamo (y recordemos que él también era natural de allí) scalfornia significa "trampas" y "engaños". Bien fuera porque sus enconados odios se fueron enfriando o bien porque ya no tenían razón de ser tal tipo de ataques a una persona que había muerto diez años antes, este párrafo (y otros similares) fueron eliminados en la segunda edición de 1513.

Se mantuvo sin embargo, con una pequeña modificación que luego indicaremos, la explicación al texto de Met.1.2, que está repartida en tres apartados, pero muy relacionados entre sí:

El primero explica la inuocatio y parafrasea lo dicho por Ovidio:

Dii coetis. Deos inuocat qui earum mutationum auctores fuerunt: ut sibi ita fauere uelint: ut quæ a principio mundi usque ad sua tempora factæ sunt mutationes: perpetuo carmine complecti possit.

El segundo, más extenso y que será motivo de nuestro análisis, explica la frase que leemos entre dos puntos en la princeps de Bolonia y también en la posterior de Bonus Accursius, o entre comas en la Romana (ambas de 1471),

\footnotetext{
putabat, Bononiam usque ubi tunc quoque degebas paedagogus, ex alpibus Bergomatum pedes ivisset, ac qui sibi magistrum Zaninum (sic enim antea in patria vocabaris) indicaret, invenire neminem posset, tandem casu tibi obviavit, ac cum dextram iungere dextrae, teque et amplexari et osculari paterna cuperet caritate, tanta impietate abs te fuit repulsus, ut eum nolueris agnoscere parentem, neque ullis blandiciis ullisve precibus, aut cuiusquam sacerdotis exhortationibus adduci potueris, ut in occulto saltem cum ipso colloquereris. Omnem igitur spem, quam in te infelix pater collocarat abiiciens, domum tristis admodum rediit. Vbi cum a vicinia tota, quidnam ageret magister Zaninus rogaretur, barbare quidem, sed non tamen inepte, Nescio ego respondit quid agat. Sed iam non Zaninus, sed Scalfornius nominator, et quidem me bene scalforniavit, hoc est magnopere decepit. Montani namque Bergomates scalfornias deceptiones atque fallacias dicunt (Raphaelis Regii Epistolae Plynii, qua libri Naturalis Historiae Tito Vespasiano dedicantur, enarrationes; Eiusdem de quattuor Persii locis, uno Valerii Maximi, duobus Tullii de officiis, ac tribus oratoriis quaestionibus disputatio; Eiusdem de quibusdam Quintiliani locis cum quodam Calfurnio dialogus; Eiusdem loci cuiusdam Quintiliani ac eius Ciceronis ad Atticum epistolae, cuius initium est: Epistolam hanc convicio efflagitarunt codicilli tui, enarratio, Venetiis: Gulielmus Tridinensis ... cuius opera hoc opusculum fuit descriptum, decimo Calendas Iunias, 1490, fol. 6r).
} 
en tanto que en la mayoría de las ediciones ${ }^{19}$ antiguas y modernas aparece entre paréntesis, un paréntesis que tiene una función ${ }^{20}$, tal como dice RR (Ven 1 y Lug fol. 1r; Par fol. 1r-v.):

nam vos mutastis \& illas. Parenthesis est, causam inuocationis continens. Cum enim dii huiusmodi mutationum fuerint auctores: facile eas memoriae scribentis suppeditare possunt. Est autem ordo. Nam \& uos mutastis illas: ac si diceret: uos \& non alii fuistis auctores huiusmodi transformationum. Est enim emphasis qua plura innuuntur: quam exprimantur. Minime uero imperitorum quorundam expositio est admittenda putantium deos in uarias figuras esse mutatos a poeta significari. Eoque sic esse ordinandum: Nam uos mutastis uos \& illas: quo quidem modo sensus ex eleganti insulsus efficeretur. Periret enim illa emphasis pulchra quae per illam \& copulam aperte demonstratur. Sed huiusmodi acuti sensus ab istis scalforniis stolidis ingenioque carentibus non percipiuntur. Causam enim assignat poeta: qua merito se deos inuocasse ostendit cum ipsi: \& non alii earum transmutationum: quas proposuit se esse expositurum: fuerint auctores. Hac autem eleganti expositione omnes non deorum solum: sed aliarum quoque rerum transmutationes comprehenduntur.

El tercero, escueto, se limita a confirmar que, por el orden de palabras y por el significado de los versos, et debe ser entendido como un adverbio:

Et.etiam.

Estas explicaciones, que se leen también en la segunda edición, con una llamada al margen para que la atención recaiga en Quorundam error y con la única sustitución de scalforniis (en los que podían estar englobados los seguidores de Calphurnius) por detractoribus (que no menciona explícitamente a su enemigo), no precisó de matización, ampliación o enmienda alguna por parte de Micyllus y, conscientemente o no, subyacen en la mayoría de ediciones, traducciones y comentarios que se han hecho hasta bien entrado el siglo XX. En cuanto a los problemas para entender su significado, ya había despertado la atención de eruditos anteriores, como demuestra que, en el s. VI, Julián de Toledo incluyera Met. 1.1-2 entre los

\footnotetext{
${ }^{19}$ Queremos dejar constancia de nuestro agradecimiento al Grupo de Investigación Nicolaus Heinsius de la Universidad de Huelva, que generosamente nos ha facilitado la consulta de aquellos manuscritos y ediciones de los que no disponíamos.

${ }^{20}$ Recuérdese el importante papel que concede a los paréntesis de la epopeya la monografía de M. von Albrecht, Die Parenthese in Ovids Metamorphosen und ihre dichterische Funktion, Hildesheim 1964.
} 
ejemplos de synchysis o "Hyperbatum ex omni parte confusum" en el parágrafo 198 del capítulo 17 (De tropis) del libro I de su Ars Grammatica, indicando para el paréntesis el mismo orden de palabras que propugnará RR: Nam \& uos mutastis illas ${ }^{21}$, con valor adverbial para la partícula et. Fueron una excepción los que entendieron el texto como esos imperiti a que se refiere $\mathrm{RR}$, a saber como si uos et illas fueran el objeto de mutastis y, por tanto, defendieran que lo que traslucen las palabras de Ovidio es que los propios dioses se transformaron a sí mismos y provocaron las otras metamorfosis, excepción personificada, como recordara Della Corte ${ }^{22}$, por C. Pascal en su edición de pasajes selectos que publicó en $1903^{23}$ y por $\mathrm{P}$. Boyancé, que en su reseña a la edición de Lafaye de "Les Belles Lettres" daba como interpretación alternativa "car vous aussi vous avez changé de formes" ${ }^{24}$, con una posible hendíadis.

La lectura illas, que ha tenido la última defensa en la monografía de $\mathrm{Cole}^{25}$, se ha visto paulatinamente desplazada en la elección de los editores por illa, que aparece como alternativa en el Erfurtensis Amplonianus prior (el $\boldsymbol{e}$ de H. Magnus ${ }^{26}$, Anderson ${ }^{27}$ y Tarrant ${ }^{28}$ ) y en el Vrbinas veterrimus de Heinsius. Tal lectio (facilior, según Cole), que aparecía recogida en el aparato crítico de ediciones anteriores, fue defendida por primera vez en 1894 por P. Lejay $^{29}$, relacionándola con coeptis, que entendió como la obra anterior de Ovidio, sus poemas eróticos, cambiados ahora a más serias empresas. Aunque con matizaciones sobre qué significa coeptis, si el simple cambio de obra o de género, tal interpretación encontró pronto entusiastas continuadores ${ }^{30}$, de lo que puede ser muestra no sólo que Tarrant la proponga en su edición

${ }^{21}$ Cf. el folio 43 de Sancti Iuliani Episcopi Toletani Ars Grammatica, Poetica, et Rhetorica. E membranis antiquiis Bibliothecae Vaticano-Palatinae nunc primum in lucem edita. Auctarium voluminis II. Patrum Toletanorum. Opera, auctoritate, et expensis eminentissimi domini Francisci Cardinalis de Lorenzana Archiepiscopi Toletani Hispaniarum primatis. et Generalis Inquisitoris. Romae MDCCXCVII, Apud Antonium Pulgonium. Praesidum facultate.

${ }^{22}$ F. Della Corte, "Il secondo verso delle Metamorfosi", Studia Florentina A. Ronconi sexagenario oblata, Roma 1970, 95.

${ }^{23}$ C. Pascal, P. Ovidi Nasonis. Ex Metamorphoseon libris fabulae selectae, Libri I-V, Torino 1903.

${ }^{24}$ P. Boyancé, “Ovide. Les Métamorphoses, L. I-X, ed. G Lafaye (Paris 1928)”, REA 32, 1930, 172.

${ }^{25}$ Th. Cole, Ovidius Mythistoricus. Legendary time in the "Metamorphoses", Frankfurt am Main 2008, 73 n. 134.

${ }^{26}$ H. Magnus, P. Ovidi Nasonis Metamorphoseon libri XV, Berolini 1914.

${ }^{27}$ W. S. Anderson Ovidius. Metamorphoses, Lipsiae $1991^{5}$.

${ }^{28}$ R. J. Tarrant, P. Ovidi Nasonis Metamorphoses, Oxonii 2004.

${ }^{29}$ P. Lejay, Morceaux choisis des Métamorphoses d'Ovide, Paris 1894, 67, n. 170.

30 Sobre todo desde que la defendió E. J. Kenney, "Ovidius Proemians", PCPhS 22, 1976, 42-53. Remitimos al estado de la cuestión y crítica que hace A. Barchiesi, Ovidio. Metamorfosi. Vol. I, Libri I-II, Milano 2005, 138-40. Más recientemente, la considera una "convinzente lezione” J. D. Reed, Ovidio. Metamorfosi. Vol. V, Libri X-XII, Milano 2013, xv-xvi. 
oxoniense $^{31}$ sino que Anderson, que en las dos ediciones con sus respectivas reediciones para la Bibliotheca Teubneriana había mantenido illas, en sus Comentarios a los libros $1-5^{32}$ y en la sexta edición, de $1998^{33}$, haya cambiado su propia lectura (illas) por illa. A tenor de la explicación de la hipálage del verso 1.1, suponemos que a RR le hubiera complacido saber que illa es una lectura posible, que tal vez él hubiera relacionado gramaticalmente con corpora, pero por el sentido con formas, ya que deja claro en su explicación que son las formas las que cambian y no los cuerpos. Menos probable, pero no imposible, es que pensara en coeptis como indicio de cambio de metro o de género, pues, aunque en la "Vida de Ovidio" que precede a su comentario subraya que está escrito en verso heroico, no tenía las mismas preocupaciones que la crítica actual sobre la poética ovidiana; con todo, atisba lo que poetológicamente es lo más característico de las Metamorfosis: ser un carmen perpetuum sin fisuras ${ }^{34}$, pese a que algunos han intentado separar los episodios mediante la inclusión de "algunas majaderías" (Ven1 fol.1r-v, Lug. fol. $1 v, \operatorname{Par} 1 v)^{35}$ :

Perpetuum: continuum: sic ut nulla transmutatio praetermittatur: alteraque alteri concinne apteque connectatur. Id quod facile a diis impetrauit poeta. Ita namque fabulam fabulæ annectit: ut una ex alia nasci uideatur: tametsi quidam non minus insulsus quam temerarius quarundam ineptiarum interpositione ea in multis exemplaribus separare conatus sit: quæ deorum benignitate tam eleganter fuerant copulata. Id uero flagitium, quo totum opus inquinibatur: in primis curaui tollendum.

Así pues, este es el tenor de este comentario escolar: deseo de explicarlo todo y excesiva seguridad en sus opiniones.

Por más que la finalidad primordial de RR no fuera la edición del texto, no le deja indiferente la corrección del mismo y advierte de cómo se ha de pronunciar o critica lecturas con las que no está de acuerdo. Por tal motivo, en su deseo de dar todo tipo de informaciones sobre los versos de Ovidio, no descuida los problemas de prosodia y métrica, que destaca tanto haciendo simples advertencias como recurriendo a explicaciones más prolijas.

${ }^{31}$ No hemos podido consultar el Vaticanus Vrbinas lat. 341 que, según Tarrant, también presenta la lectura illa en su tercera corrección "gótica" $\left(\mathrm{U}^{3}\right)$.

32 W. S. Anderson, Ovid's Metamorphoses: Books 1-5, Norman-London 1977.

${ }_{33}$ W. S. Anderson Ovidius. Metamorphoses, Berlin 1998, publicada por De Gruyter.

${ }^{34}$ Cf. M $\mathrm{M}^{\mathrm{a}}$ C. Álvarez, R. Ma Iglesias, “Introducción” a Ovidio. Metamorfosis, Madrid 2015 57-89 con la bibliografía allí citada.

${ }^{35}$ Calificación que más bien merecerían los resúmenes de argumentos o del contenido de las fábulas, que aparecen en más de una edición, sin que sean necesariamente los de Lactancio. 
Una sencilla aclaración es la nota a 1.422-3, a propósito de los animales que los egipcios encontraron en el cauce del Nilo, pues, tras explicar la razón del epíteto septemfluus del río ${ }^{36}$, nos advierte de que en la última palabra del verso 1.423 (Nilus et antiquo sua flumina reddidit alueo) hay una sinéresis, recurso que define sin que crea necesaria más aclaración (Ven1 fol. 10r, Lug fol. $13 r$, Par fol. 12r):

Alueo. Syneresis est duarum uocalium in unam.

También en los comentarios escolares de la segunda mitad del siglo XIX se advertía de tal sinéresis o sinicesis: así Siebelis-Polle, que quisieron hacer un comentario completo de una selección de las Metamorfosis, al llegar a este verso, el 258 de su selección, indican que hay sinéresis ("lies zweisilbig") y remiten a la explicación dada con anterioridad al $191(=1.353)$ donde a propósito de deinde (término en el que no había reparado RR), explican en qué consiste el recurso y enumeran otras palabras que pueden ser analizadas de modo similar, entre las que destacan alveo y aurea, siempre al final del verso ${ }^{37}$. De igual forma M. Haupt anota alveo como "zweisilbig durch Synizesis" desde la primera edición de su comentario en $1853^{38}$, explicación que se mantiene sin añadidos a lo largo de las reediciones berlinesas en colaboración con O. Korn y que se ve ampliada cuando en 1903 se incorpora H.J. Müller ${ }^{39}$, pues recuerdan otros cinco lugares en los que hay sinéresis, coincidiendo en dos de ellos con RR: Nelei de 2.689 (Ven1 fol. 25r, Lug 33v, Par fol. 29r) y aureae de 7.151 (Ven1 fol 67r, Lug fol. 104r, Par om. ${ }^{40}$ ); a esta última sinéresis le añade RR una explicación alternativa:

Nisi malimus dicere versum esse hypermetrum cum praesertim sequens versus incipit a uocali.

${ }^{36} \mathrm{Da}$ a continución el nombre de las siete bocas según el orden de Diodoro de Sicilia 1.33, 7, para lo que sin duda se vale de la traducción de Poggio Bracciolini publicada en Bolonia en 1472 o de la veneciana de 1476: Diodori Siculia Historiarum priscarum libri, e graeco in latinum traducti per Fr. Poggium. accedit Cornelii Taciti de Situ, Moribus et Populis Germaniae libellus aureus. Bononia MCCCCLXXII; Venetiis MCCCCLXXVI.

${ }^{37}$ J. Siebelis, F. Pole, P. Ovidi Nasonis Metamorphoses, Erste Heft, Buch I-IX, Leipzig 1873. En la p. 24 hacen el comentario de alveo y en la 21 leemos: Deinde zweisilbig, indem die beidem ersten Silben zu einer verschmelzen: Sinäresis od. Synizesis. Bei den Wörten deinde, Persei, deorsum uä. ist dieselbe an jeder Stelle des Verses gewohntlich, bei aurea, alveo u ä nur am ende des Verses zu".

${ }^{38}$ M. Haupt, Die Metamorphosen des P. Ovidius Naso, Leipzig 1853, 24.

${ }^{39}$ M. Haupt, O. Korn, H. J. Müller, R. Ehwald, Die Metamorphosen des P. Ovidius Naso, Berlin 1903, 44.

${ }^{40}$ Sin duda por un error en la imprenta al organizar los cuadernillos, el ejemplar de la “edición de Parma" conservado en Murcia pasa del v. 7.74 (fol. $75 r$ ) a 7.159 (fol. 75v), tanto en el texto como en el comentario que lo enmarca. 
No siempre resalta $\mathrm{RR}$ las sinéresis que se puedan encontrar en determinados términos, sobre todo si está más preocupado por la correcta pronunciación de un nombre propio. Esa es la razón de que no advierta que en 3.303, el final del hexámetro (igne Typhoea) sólo se puede leer correctamente si se recurre a contraer ea en una sola sílaba. Su interés está en que se vea el hiato (Ven 1 fol. 31r, Lug fol. 42r, Par fol. 35r):

Est autem trisyllabum nomen: nec unquam o \& e vocales in unam syllabam nisi figuratae iunguntur: ultima enim est diphthongus: non secunda ut quidam putant

Esa misma explicación, insistiendo de nuevo en que no se diptongue -oe-, la repite casi con las mismas palabras, cuando, al comentar 5.321 (emissumque ima de sede Typohea terrae), determina el número de sílabas de Typhoeus (Ven 1 fol. 51r, Lug fol. 70v, Par fol. 58r):

Sane Typhoeus ita trisyllabum est, ut non o \& e: sed e \& u in diphtongum copulentur. quidam enim de orthographia scribentes cum oe diphtongo hoc nomen scribendum stulte praecipiunt.

Al decir que es trisílabo, RR se equivoca, pues no se percata de la diferente escansión del nombre del gigante según la posición en el verso, como vio Bömer ${ }^{41}$ a propósito del acusativo de 3.303 . En efecto, si va en final de verso sufre sinéresis (sea nominativo como en 5.353 o acusativo), pero cuando Typhoea no está en final (como ocurre en Met. 5.321, 325 y 348) hay que medirlo como un tetrasílabo. Por lo tanto, yerra el humanista al insistir en el carácter trisilábico de este término. Posiblemente la lectura que critica RR pudiera derivar de la consulta, directa o a través de intermediarios, de los manuscritos medievales que escriben o bien Tifea o Tifoea, claro indicio de que lo entendían como diptongo. En el aparato crítico de la edición de Hugo Magnus se indica para ambos versos que thiphoea y typhea se leen en el ms. F (Marcianus Florentinus 223, del s. XI), tiphea en el 1 (Laurentianus 36,12, del s. XII), tipheum en el f (corrección hecha en el s. XIV del F), por lo que está sobradamente justificada la preocupación de RR, máxime si nos percatamos de que ya Naugerius en 1515, según se deduce de la edición de Regius-Micyllus (Bas fol.145) y de las reimpresiones de la del propio Navagero en 1582 y de $1595^{42}$, tuvo cuidado en señalar el hiato entre $o$ y $e$ con una diéresis, una línea horizontal o un ictus sobre la $e$ y los editores modernos con una diéresis sobre la segunda vocal (Typhoёa), pero todavía hoy existen diccionarios de mitología

${ }^{41}$ F. Bömer, P. Ovidius Naso, Metamorphosen, Komm., vol. I (B. I-III), Heidelberg 1969.

${ }^{42}$ P. Ovidii Nasonis Metamorphoseon libri XV. Ab Andrea Naugerio castigati, \& Vict. Giselini Scholiis illustrati, London 1582; Id. Antverpiae 1595. 
o estudios sobre el gigantesco Tifoeo que lo llaman erróneamente Tifeo, monoptongando el inexistente diptongo, es decir, considerando trisílabo lo que un nombre de cuatro sílabas que debe transcribirse como "Ti-fo-e-o".

$\mathrm{El}$ interés por la corrección métrica, que se detecta a lo largo de la obra ${ }^{43}$, no desaparece en los años que transcurren entre la primera y la segunda edición, pues en 1513 observa a propósito del segundo hemistiquio de 2.247 (et Taenarius Eurotas) que debe buscarse una escritura alternativa para Taenarius, ya que de mantenerse habría un yambo en el $4^{\circ}$ pie (Ven $231 r$, Bas. fol. 43):

Taenarieus autem est legendum, ut quattuor syllabarum sit, et in diphthongum desinat, ne iambus, quem non admittit versus heroicus, in quarta sede positus esse videatur.

Este "problema" métrico lo solucionó Micyllus, haciendo ver la corrección de la lectura Taenarius, que alarga en arsis y ante cesura ennemímera, explicación que ha sido mantenida por los comentaristas posteriores:

Frustra Curiosus est hoc loco Regius. Nam \& Tenarius absque diphthongo recte legitur, \& versum brevis syllaba non minuit, cum sit in arsi et tome. Nam eodem modo \& illa defenduntur.

No tuvo reparos $R R$ en enmendar las lecturas de la edición que había tomado como base de su comentario. Entre esas enmiendas destacamos:

El verso 3.480 lo lee en la mayoría de las ediciones y códices que tiene a mano así: dumque dolet: summo uestem diduxit ab ore. Pero sugiere que summno $a b$ ore puede tener como lectura alternativa summa $a b$ ora (Ven 1 fol. $33 r$, Lug fol. $54 v$, Par fol. $37 v$ ):

$A b$ ore summo. Sic quidem legitur. Sed ab ora summa forsitan ab Ouidio fuit scriptum: ut a superiore extremitate uestem fuisse diductam intelligamus. Nam ora uniuscuiusque rei non solum terrarum extremitas appellatur.

También Naugerius consideró la conveniencia de leer summa ab ora, aunque el verso que él transmite (y que numera como 460) no es idéntico al de RR:

${ }^{43}$ Otro ejemplo está en el comentario a 5.274, en el que diferencia el trisíbabo Pyreneus, el salvaje acosador de las Musas, del tetrasílabo Pyrenaeus, nombre de la cordillera (Ven 1 fol. $51 r$, Lug fol.69v, Par fol. 57v): Pyreneus sane nomen esse trisyllabum: non: ut quidam putant: quadrisyllabum: nisi pro monte accipiatur: quo Gallia ab Hispania disterminatur. Tunc enim penultima cum $\propto$ diphtongo scribitur. 
dumque dolet: summo vestemque reducit ab ore. Ista in omnibus, nos tamen legendum credimus summa ab ora.

Ciofanus, sin tomar en consideración la opinión de Naugerius, rechaza la sugerencia de RR y da su propia explicación ${ }^{44}$, recurriendo a lugares paralelos del propio Ovidio, sin reparar en que tales ejemplos de Amores y Metamorfosis refuerzan la hipótesis de RR de que se lea ab ora summa:

summa vestem diduxit $a b$ ora] Non sane video, quare Regius a lectione, quam repererat, recesserit. Tu hoc modo lege, adiuuantibus optimis libris s. Summo vestem deduxit ab ore. In duobus Caelest. Abb. \& Briantij, \& Io. Dei, summo vestemque reduxit $a b$ ore. Ab ore, hoc loco, valet a pectore, vnde vestis incipit; vel, quoniam loquitur de mare, ab ore, hoc est a mento vel collo. Os enim apud Latinos pro tota facie ponitur. Quin etiam pro tota illa, quæ cernitur, parte. Deduxit, hic significat, lacerauit. Vt apud hunc ipsum poëtam. Alibi: Aut tunicam summa deducere turpiter ora? (Am. 1.7.47) Et in lib. v. summa vestem laniaret $a b$ ora (Met. 5.398). quod fortasse Regium, vt ita legeret, decepit. Periculosum, \& temerarium saepe est, ab antiquis libris discedere.

Nicolaus Heinsius no compartió la opinión del humanista sulmonense y defendió como "recte" ${ }^{45}$ la expresión summa vestem deduxit ab ora, basándose precisamente en el mismo verso 5.398 que Ciofanus había recordado para oponerse a RR.

Y, si bien no siempre coincidiendo con la forma verbal (diduxit, reduxit, reducit), la sugerencia de $\mathrm{RR}$ es recogida y aceptada por los mejores editores $^{46}$; así $\mathrm{H}$. Magnus, que en su aparato crítico indica para tal lectura Regius vulgo, o más recientemente Anderson y Tarrant, que sólo aluden a su existencia en algunos manuscritos sin citar a RR como el primer autor de la lectura corregida.

RR se muestra mucho más categórico cuando propone que se cambie una lectura si basa su argumentación en sus conocimientos mitológicos. Ya en la primera edición quiere cambiar el texto que leyera en B. Accursius para 7.158 (victor cecropios tetigit cum coniuge portus) sobre la llegada a tierras griegas de Jasón y Medea. Describe las fases de su análisis, a partir de lo que lee en algunos códices, hasta llegar a la que considera la lectura definitiva, que

${ }^{44}$ Observationes, 67-8.

${ }^{45}$ N. Heinsius D. F., Notae in Metamorphoses P. Ovidii Nasonis, Amstelædami 1659, 68.

${ }^{46}$ Para las distintas variantes textuales, cf. A. Suárez del Río, Edición crítica y comentario textual del libro III de las Metamorfosis de Ovidio, Tesis Doctoral, Universidad de Huelva 2015, 343-5. 
no ha encontrado en los manuscritos, por lo que en esta ocasión sí podemos hablar de conjetura (Ven1 fol. 67v, Lug 92v, Par 75b):

Cecropios portus. Sic quidem fere legitur. sicque legendum esse quoque olim contendi. Nunc cum in uetusto exemplari animaduerterim Colchiacos scriptum esse facile in eam sum adductus opinionem: ut sentiam colchiacos in Iolciacos esse commutandum. Est enim Iolcos que \& Iaolcos dicitur ab Homero: urbs Thessaliæ Iasonis pátria ab Iolco Amyri filio dicta: ut Stephanus de urbibus scribit. Vnde Iolcius \& Iolciacus declinatur. Tametsi is qui hoc egregium opus e latina in graecam linguam transtulit:

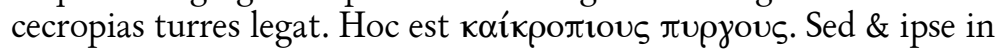
deprauatum inciderat exemplar.

Vemos que en principio le había convencido la lectura cecropios portus, que estaba ya en la edición príncipe de Bolonia (1471) y que, según el aparato crítico de la edición de Hugo Magnus, es la de los mss. F(Marcianus Florentinus, S. XI-XII), 1 (Codex Laurentianus 36,12 = L de Anderson y Tarrant), $\mathbf{g}$ (codex Graecensis 1415, del s. XII) y el pequeño grupo de códices heinsianos que agrupa bajo la sigla $\varsigma$, a los que hay que añadir los que Anderson llama W (Vat. Lat. 5859, de 1275) y $\mathbf{v}$ (Vat. Lat. 1593, del s. XII), además de figurar en la tercera edición de Venecia de 1486, también según Magnus. Esta lectura será rechazada igualmente, como veremos, por Ciofanus.

RR cambió de opinión cuando vio en un "antiquísimo ejemplar" (que bien pudieran ser los mss. que más crédito ofrecen a los editores, $\mathbf{M}$ y $\mathbf{N}$, ambos de finales del siglo XI y comienzos del XII), el término Colchiacos; sus conocimientos del mito le indujeron a cambiarlo por Iolciacos, pues sin duda sabía que Jasón había partido del puerto de Iolco y que allí arribó procedente de la Cólquide; pero, para confirmar lo acertado de su deducción, recurrre a lo que lee

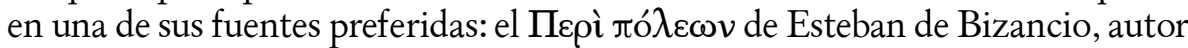
al que no consultaría (suponemos) en el ejemplar de la biblioteca de Calfurnio, como tuvo ocasión de hacer Láscaris en su estancia en Padua de 1491, pero que conocía bien y contribuyó a difundir mediante perífrasis y traducciones muchos años antes de que viera la luz la primera edición aldina con traducción de 1502. Al gramático y geógrafo bizantino le debe la información sobre Iolco, ciudad de Tesalia ya citada por Homero como Iaolcos (Il. 2.712), cuyo epónimo fue un hijo de $\mathrm{Amiro}^{47}$, y que da lugar a adjetivos de diferentes formas:

${ }^{47}$ Hemos utilizado la prestigiosa edición de Pinedo, que recoge este pasaje en $1340 \mathrm{G}$ :

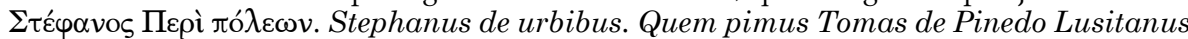
Latii jure donabat, \& Observationibus Scrutinio Variarum Linguarum, ac procipuè Hebraicce, Phoeniciœe, Graecœ \& Latince detectis illustrabat, His additis proter ejusdem Stephani Fragmerntum Collationes Jacobi Gronovii cum codice Perusino, Unà cum gemino Rerum \& Verborum Indice ad Stephanum et Tomce de Pinedo Observaciones, 


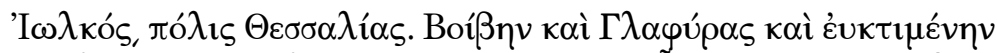

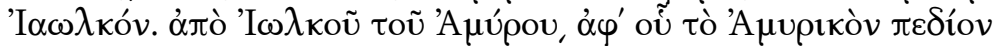

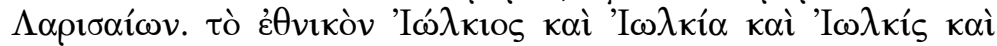

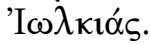

Además, no quiere RR que parezca que no conoce la obra de Planudes, el monje bizantino que tradujo Metamorfosis y Heroidas al griego a finales del s. XIII, pero advierte de que se ha servido de un original latino equivocado y

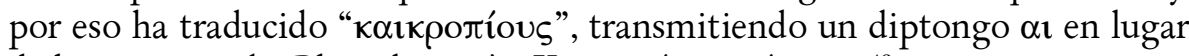

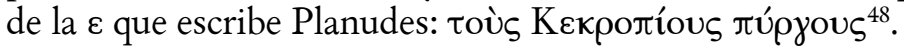

Esta propuesta, que bien puede tildarse de conjetura, aparece modificada en la segunda edición ( $y$ por tanto en la completada por Micyllus, que nada añade al respecto), sin que podamos afirmar que influyera en ello la edición Aldina de 1502. Tales modificaciones consisten (Ven2 fol. 82r, Bas fol. 154) en:

- La lectura que dice haber aceptado en un principio es Colchiacos portus en lugar de Cecropios $p$.

- Lo que leyó en un antiquísimo códice no es Colchiacos sino Iolciacos, que propugna de nuevo como la adecuada.

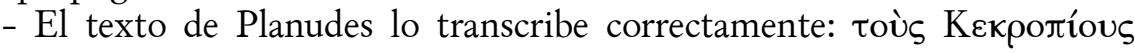

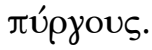

Esta segunda redacción fue sin duda la que llegó a manos de Ciofanus, que no cree en las palabras de RR y deduce un proceso que está casi en la misma línea del que el comentarista informaba en su primera edición. Dice Ciofano ${ }^{49}$ :

Victor Iolciacos tetigit cum coniuge portus] Testatur hoc loco Regius ita legi hunc versum in vetusto exemplari. Quod rerum fuisse non puto. Illud potius crederem, eum, coniectura fretum, vt ita lergeret, in hanc venisse opinionem. Ego enim hoc loco scriptos omnes libros diligenter inspexi, in quorum nullo est lectio, quam Regius se inuenisse affirmat. Itaque in plerisque erat: Victor Cecropios tetigit, \& reliqua.

Tiene razón Ciofanus al denunciar que no exite la lectura Iolciacos en los códices, a no ser (matizamos nosotras) en los corregidos en el s. XVI. Por otra parte, el sulmonés defiende Haemonios, que, por más que contara

Amstelodami, Typis Jacobi de Jonge, 1678.

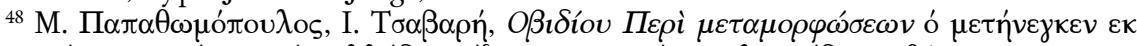

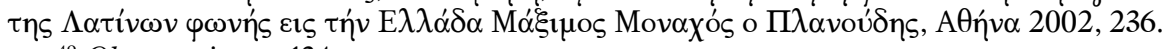

${ }^{49}$ Observationes, 134. 
con la aprobación del gran erudito ciceroniano Paulus Manutius, no ha sido aceptada, aunque sí citada, con posterioridad ${ }^{50}$.

Gierig en su edición de 1784 escribió en el aparato crítico sobre el v.7.158: Vulg. Colchiacos, quod Regius recte in Iolciacos mutavit, lo que hace pensar en la primera edición. Similar información encontramos en la edición de Baumgarten-Crusius de $1834^{51}$.

En cambio Ehwald, que escribe en 1915 "Iolciacos cod. Raph. Regii", y Magnus (1914), con su "Iolciacos vetustum exemplar Raph Regii", parecen tener en cuenta la segunda edición o la micylliana.

De los editores más recientes, sólo Anderson explicita que Iolciacos aparece recogido en la cuarta corrección, humanista, del ms. U (Vaticanus Urbinas 341), como consecuencia de la propuesta del bergamasco.

También ha sido fundamental la opinión de RR para la correcta transmisión de Met.12.110, en cuya exégesis ${ }^{52}$ no ha sido superado por ningún comentarista posterior. Demuestra conocer la geografía pero sobre todo la mitología troyana y por ende la Ilíada para defender la lectura que considera correcta (Ven 1 fol. 117v, Lug fol. 160v-161r, Par fol. 130r):

Solus Echionias corrupte quidem sic legitur eorum culpa: qui sibi omnia permittunt in iis inuertendis: que in priscis exemplaribus descripta non percipiunt. Cum enim quasnam Ouidius Aeetionias Thebas uocaret: minus intelligerent homines \& imperiti \& temerarii: non solum Aeetionias in Echionias inuerterunt: sed hoc quoque nomen Solus ex commodo suo ascripserunt: ignorantes Echionias Thebas in Boeotia esse: quæ pro Græcis contra Troianos senserunt: ut aperte in secundo iliados narrat Homerus. quas autem se iactat

\footnotetext{
${ }^{50}$ Leemos en las pp. 134-5 de Ciofanus: In vno meo apertè legitur: Victor ad Homonios intrat cum coniuge portus. In vno Vatican. Haemonios victor tetigit cum coniuge portus. Quæ quidem lectio illam libri mei non parum adiuuat, ac fulcit. Quam hic noster hac de re loquens alibi etiam confirmat (Her. 6.23-4) ... et rursus multo magis (Her. 12.127-8) ... Lectionem libri mei probauit is, cuius famam nulla vmquam delebit obliuio, optimus clarissimus vir, Paullus Manutius, Cuius ex obitu Romae anno MDLXXIV., oct. Id. A prilis sub horam vigesimam, magnam Latinus sermo accepit iacturam. Is in epistola, Quam, cùm ab eo hoc cognoscere auerem, ad me misit, ita scribit. Estque ita in manibus. P. MANVTIVs HERCVLI CIOFANO s. Non possum non amare vehementer industriam tuam, qua te vti video in emendando gentili tuo, poëta summo. Perge, vt cœpisti. Nam \& gloriæ tuæ consules, \& alios ad eandem laudem excitabis. Victor ad Haemonios, magis arridet, quàm, Victor Iolciacos: accedente præsertim antiqui libri testimonio. Regius autem, inania captans, veritatem quærebat in tenebris. Tu longè certiora sequeris. Itaque tibi libenter assentior. Vale. Roma XIII Kal. Apr. MDLXIX.

${ }^{51}$ C. G. Baumgarten-Crusius, P. Ovidi Nasonis Metamorphoses, Lipsiae 1834, 253.

${ }^{52}$ Cf. R. Ma Iglesias Montiel, Mํㅡㄹ C. Álvarez Morán, "La Leyenda Troyana en la mitografía humanista II: Los siglos XV y XVI”, en J. M ${ }^{a}$ Maestre et al., coord., Humanismo y Pervivencia del Mundo Clásico III. Homenaje al Profesor Antonio Fontán, Alcañiz-Madrid 2002, 1769-70.
} 
expugnasse Achilles in Cilicia, sunt Aeetioniæ dictæ ab Aeetione Andromaches patre: quem ab Achille interfectum Thebenque urbem Ciliciæ excelsam fuisse depopulatam apud Homerum Andromache ipsa conqueritur. Thebæ autem multarum urbium est nomen... Thebæ sane Ciliciæ pro Troianis contra Græcos arma sumpserunt.

En estas palabras se trasluce la irritación que en él despierta que homines \& imperiti \& temerarii hayan cambiado el adjetivo que acompaña a Tebas, la ciudad que, según palabras del propio héroe, fue devastada por Aquiles, pues la han llamado "Equionia", como si de la Tebas de Beocia se tratase, en lugar de calificarla con el adjetivo que recuerda al padre de Andrómaca. Pero sobre todo le parece inadmisible que también por ignorancia hayan incluido el término solus delante del gentilicio. La secuencia Solus Echionias se lee en las dos ediciones príncipes de 1471 (Bolonia y Roma), así como en las que Bonus Accursius publicó en Vicenza (1480) y en Venecia (1492), basándose sin duda en manuscritos antiguos; así aparece en N (ss. XI-XII): Solus echi ${ }^{\circ}$ neas y, con leves variaciones, en F (también de los ss. XI-XII), e (Erfurtanus, ss. XII-XIII), h (Hauniensis, s. XIII) y en el grupo de heinsianos agrupados por Magnus con la sigla $\varsigma$, a los que él añade la tercera edición de Venecia de 1486. Otros manuscritos no menos prestigiosos presentan Sic et ante el adjetivo: echinias en M (s. XI-XII) y echionias en el que Magnus llama $\mu$ (Codex Monacensis $23612=\mathrm{m}$ de Tarrant, de fines del XII). RR, quien, como hemos visto a propósito de la conjetura Iolciacos, había

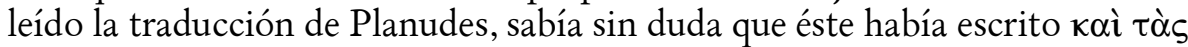

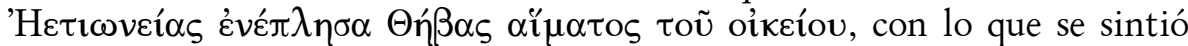
"autorizado" para criticar la lectura errónea y proponer que se restituyera lo que para él era el término escrito por Ovidio: Aeetionias, que no es una correcta transcripción, pero sí es un buen ejemplo de cómo en latín, lengua vulgar y medieval, la $\mathrm{H}$ (eta) griega (larga y abierta) fue transcrita por $Æ$ y el diptongo EI (que ante vocal se transcribe por E larga en latín clásico) suele evolucionar a I larga.

Fue pronto bien acogida por los editores la corrección de nuestro comentarista, pues ya en la edición aldina de 1502 leemos: Aeetionias impleui sanguine Thebas. Y en las ediciones modernas abre el verso 12.110 Eetioneas en su forma correcta, en especial gracias a Heinsius. Atribuye Magnus tal lectura a la transcripción de la obra de Planudes, sin reparar en que también RR mencionaba el adjetivo Eetioneas para cubrir todo el primer hemistiquio, pues al final de su explicación de las dos diferentes Tebas, la de Beocia y la de Cilicia, y de por qué ha de ser ésta y no la griega, añade en la segunda versión (Ven2 fol. 131rv): legitur etiam Eetioneas, que también se 
lee en la ampliada por Mycillus (Bas fol. 288) $)^{53}$, quien se limita a reproducir los versos de Homero en que aparecen tanto la ciudad de Tebas como su rey Eetión, el padre de Andrómaca.

Su preocupación por la exactitud de los nombres hubiera merecido que fuera ovidiano y no espurio el verso que, a continuación de la alusión que se hace a una Tegea en 8.317 (nemorisque decus Tegeaea Lycaei), leía RR en manuscritos y ediciones: venit atalantis conei pulcherrima uirgo, con una genealogía que no le parece adecuada y que le lleva a propugnar el cambio de nombres de hija y padre, así como diferenciar las dos Atalantas que aparecen en los textos clásicos:

Venit atalantis ccenei: sic quidem legitur: sed Atalante \& Schoenei mihi recte a Græcis legi uidetur. nam Atalanta \& Schoenei filia fuit formosissima, ex qua Meleager Parthenopeum suscepit. altera fuit Atalanta, Iasii, filii Abantis, Argiuorum regis filia. de que Propertius [I 1, 9], Milanion nullos fugiendo, Tulle labores Sæuitia, duræ contudit Iasidos

En efecto, con pequeñas modificaciones, ésta es la lectura que dan, además de los códices recentiores heinsianos, manuscritos de los siglos XI y XII: el $\mathbf{P}$ (Parisinus Latinus $8001=\mathbf{B}$ de Tarrant) y sobre todo el $\mathbf{M}$, posiblemente leído en el s. XIV por Boccaccio, pues en su Genealogia Deorum 9.19 dice a propósito de los participantes en la Cacería de Calidón:

cum vocatu Meleagri convenissent omnes adiacentium civitatum insignes iuvenes, contigit ut et Athlas virgo Cenei filia, seu secundum alios Jasij regis, forma et etate conspicua, et venationum experta etiam advocata veniret.

Esa misma genealogía, incorporada a los márgenes de los manuscritos $\mathbf{F}$ y $\mathbf{N}$ corregidos en siglos posteriores, está también en las primeras ediciones, aunque con pequeñas variantes en el nombre de la joven arquera: en la princeps romana se lee Adlantis Cenei, en tanto que en la princeps de Bolonia Athlantis C. y en la de 1492 de Bonus Accursius Athalantis C. Pero RR cree que los griegos los llamaban respectivamente Atalante y Schoeneus, deducción a la que sin

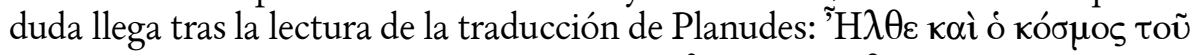

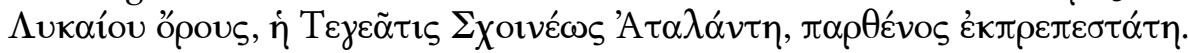
Notemos, además, que en su exégesis aprovecha para diferenciar dos Atalantas, la beocia hija de Esqueneo y la argiva hija de Iasio, con lo que corrige sutilmente la identificación que Boccaccio hiciera en su G.D.

\footnotetext{
${ }^{53}$ Por error en la numeración, aparece como fol. 248.
} 
Micyllus (Bas fol. 190) se percata de la dificultad métrica que tiene la secuencia Venit Atlantis y menciona otras soluciones: Venit et A. o Venatrix $A$., pero se rinde a la evidencia y concluye: quare \& hunc uersum inter incertos \& inexplicatos relinquemus, sin hacerse eco de que ya lo había considerado espurio en 1516 Naugerius, quien dice a propósito del verso 317:

nemorisque decus Tegecea Lycei. Quod post hoc sequebatur carmen. Venit Atalanta Schenei pulcherrima virgo, tum quia in veteribus non invenitur, tum quod \& sillabis claudicat, \& rude ac nihili est, reijciendum duximus.

Abundará en esa opinión Ciofanus:

At sequens carmen: Venit Atalanta Schœnei pucherrima Virgo, non legitur in libris quotquot vidi. Quare non mirum videri debeat, si alij id obelo notarunt. Ego, veterum librorum fretus fide, \& auctoritate, supposisisium, atque adulterinum puto. Itaque omnino expugnendum reor. Nam primùm ineptum est, nostroque indignum poëta: deinde, quod potissimum est, abest, vt dixi, ab antiquis exemplaribus. Quin etiam absque eo sensus optimus est, optimeque superius cum sequenti cohæret.

Como se ve, reproducen la lectura propugnada por RR Atalanta Schoenei. Los argumentos para rechazar este verso como no ovidiano fueron determinantes y ningún editor moderno lo incorpora, pero sí lo citan en los respectivos aparatos críticos. Tal vez fue introducido por algún copista que no supo interpretar quién era la Tegeaea del verso anterior y, sabiendo que toda la descripción posterior está referida a Atalanta, "fabricó" un verso que aludiera a ella, pero que, aunque perfecto en el segundo hemistiquio (coincide con el de Met. 9.9 referido a Deyanira), es totalmente incorrecto en su primera parte, pues obligaría a que hubiera 2 yambos en el segundo y tercer pie. Tal vez el autor de este mal hexámetro quiso imitar a los autores de centones, pues la primera parte parece inspirada en 8.627: Venit Atlantiades, de métrica correcta.

Hemos dejado para el final dos propuestas de RR, ambas del libro II, que sólo aparecen en la segunda edición de 1513, lo que demuestra su continuada dedicación a la exégesis de la obra de Ovidio.

La primera ofrece en 2.454 una alternativa a la lectura que se lee en casi la totalidad de manuscritos (Ven2 fol. 23v, Bas. 49a), sin que Micyllus añada nada:

Cum dea uenatu: sic quidem fere legitur: sed in uetusto exemplari uenatrix rectius mihi scriptum esse uidetur: ut sit Dianę periphrasis. 
No sabemos cuál sería ese vetustus exemplar, cuya existencia pone en duda Ciofanus, al tiempo que rechaza la postura de RR con fundadas razones, entre otras que no lo ha encontrado en los libros antiguos ${ }^{54}$ :

Cum dea uenatu] haec lectio reiicitur à RR, iniustè, vt puto: cùm ait legendum esse Venatrix: vt sit Dianæ periphrasis. Bis enim superius de ea mentionem fecit. Quare superfluum ac superuacaneum videri potest tertio epitheton ponere. Venatrix abest à vet. libris: neque est, quod dicat mihi, legi in vno: cùm, vt dixi, abest à libris, quotque vidi.

Pero sí estaba entre los códices que consultó Heinsius ${ }^{55}$, quien, sin citar a $\mathrm{RR}$, considera adecuada la lectura ${ }^{56}$ : venatrix rectius in nonnullis antiquis. Citan a ambos humanistas (a Regius y a Heinsius) como garantes de esta lectura, $\mathrm{Jahn}^{57}$ y H. Magnus en sus prestigiosas ediciones, pero el nombre de RR ya no está en la edición de Anderson, quien atribuye solamente al sabio holandés la defensa de tal lectio; Tarrant, por su parte, indica en qué manuscritos de menos importancia aparece venatrix sin mencionar garante alguno.

El último ejemplo que aportamos no ha tenido eco en las ediciones posteriores a RR y, a nuestro modo de ver, con razón. No se trata de una lectura encontrada en algún manuscrito sino de su deseo de que se lea el nombre de Aglauro, una de las hijas de Cécrope, como Agraulo, relacionándolo con el campo. Y la explicación que da a propósito de 2.555 es la siguiente (Ven2 fol. 35r):

Gemino de Cecrope: Ei tres filiæ fuerunt Pandrosos, Herse, Aglauros, quibus nomina indidit ab iis: quibus fruges maximæ

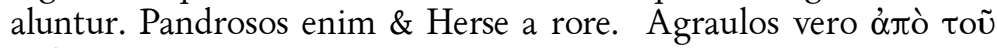

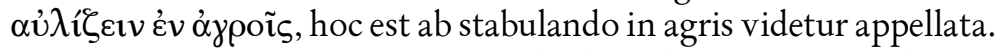
$\mathrm{Nec}$ ignoro me, ut est in exemplaribus depravatum, Aglauron legisse et exposuisse, nuper vero animadverti Agraulon ea de caussa, quam scripsi, fuisse nominatam. Quare Agraulos ubicunque Aglauros hactenus lectum est, mihi videtur esse reponendum, ne a graecis scriptoribus, unde sum admonitus disentire coarguamur, tametsi Pausanias in Atticae descriptione illam Aglauron mendose, ut puto, vocat.

${ }^{54}$ Observationes, 40-1.

${ }^{55}$ En tres, según Slater, en el aparato crítico correspondiente a este verso en D. A. Slater, Towards a text of the "Metamorphosis" of Ovid, Oxford 1927.

${ }^{56}$ Notes, 38.

${ }^{57} \mathrm{~J}$. Chr. Jahn, P. Ovidii Nasonis Mertamorphoseon libri XV, vol. I, lib. I-VII, Lipsiae 1832. 
La afirmación de que los nombres de las hijas de Cécrope derivan de aquello de lo que se nutren las cosechas es traducción de Esteban de Bizancio

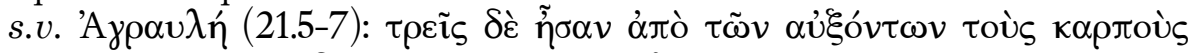

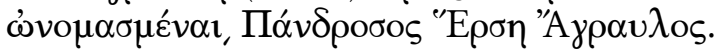

Pero que Pándroso y Herse significan el rocío parece tomarlo de una adaptación de los nombres a la lengua latina, de ahí que los relacione con ros, roris.

En cuanto a la lectura Agraulos, la toma del mismo lugar de Esteban de Bizancio, y lo amplía diciendo que significa "pasar el tiempo en los campos" 58 , y por ello debe ser Agra-, aunque él mismo ha leído e incluso ha escrito en ocasiones Aglauros.

La caussa quam scripsi, la encontramos en la Apologia del libro II, que sigue inmediatamente a la carta dirigida a Philippus Cyulanus, destinatario de la segunda edición, y que en la micylliana va al final de la exégesis ${ }^{59}$ :

Varie quidem $a b$ auctoribus græcis huius puellæ nomen scribitur. Nam Pausanias in Atticæ descriptione [1.2.6], nisi mendum inest, Aglauron ut latini illam vocat. Alii vero græci, quos quidem ego viderim, Agraulon. Itaque correxi: quamuis Hellanicum, qui in eruditionis ostentationem a quibusdam citatur, cum nusquam extet, nondum legerim.

Según Frazer, en nota a Apoll. 3.14.1-2 ${ }^{60}$, el único lugar en el que se llama Agraulo a la hija de Cécrope es precisamente en Apolodoro, mientras que Aglauro no sólo es literario sino que aparece en inscripciones de vasos griegos. Puesto que no tenemos indicios de que RR pudiera conocer el texto de la Biblioteca, cuya princeps apareción en Roma en 1555 de la mano de Benedictus Aegius y acompañada de la correspondiente traducción latina, y dado que no hemos podido localizar el lugar de Helanico al que alude, todo hace suponer que el modelo directo para RR es Esteban de Bizancio, autor al que conocía bien; sin duda la publicación en 1502 de la princeps Aldina del geógrafo griego le pudo hacer pensar en el cambio de nombre para la hija de Cécrope.

Por su parte, Micyllus (Bas. fol. 52) mantiene Aglauros (como Suidas y Pausanias) y de ella dice que significa splendidum ac pulchrum, quasi

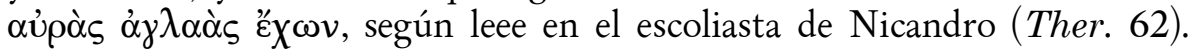
Apunta también otras posibles explicaciones: que Aglauro fue así llamada por ser triste y envidiosa (lo contrario del significado de su nombre, explicación

${ }^{58}$ Es un adjetivo propio de animales, Cf. $I l .10 .155$ (hablando de bueyes), 18.162 y otros muchos textos posteriores.

${ }^{59}$ Bajo el título Apologia Raphaelis Regii contrà quosdam cauillatores. Primi Libri... Secundi Libri...

${ }^{60}$ J. G. Frazer. Apollodorus. The Library, London 1979, II, 81, n.3. 


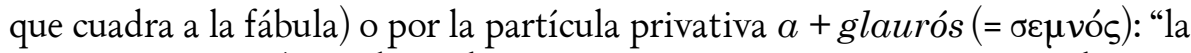
que es poco $\sigma \varepsilon \mu \nu$ n’", es decir "la que no venera" primero a Minerva y luego a Mercurio. Es, por tanto, totalmente opuesto a RR, pues afirma que Aglauro nunca estuvo en el campo, ya que Mercurio la encontró en la Acrópolis. Lo

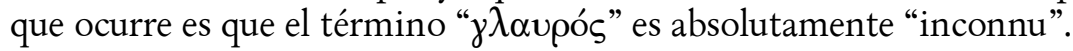

Queda claro, pues, que RR no solamente se ocupaba de cuestiones elementales en sus anotaciones sino que se preocupaba de la corrección léxica, prosódica y métrica, e intentaba aclarar cuestiones que todavía hoy deben ser tenidas en cuenta, como es el caso del nombre de Tifoeo; $y$, además, de su atenta lectura de todos los mss. que tenía a su alcance, sea cual fuera su calidad, deducía enmiendas, muchas de las cuales han sido aceptadas o discutidas por la crítica a lo largo de los últimos siglos, entre las que podemos destacar Iolciacos para 7.158 o Eetioneas en 12.110; si bien, excepcionalmente, yerra. 